\title{
Katı Atık Toplama ve Taşıma Sisteminden Kaynaklanan Hava Kirleticileri Emisyonlarının Mekansal Analiz Teknikleri ile Farklı Araç Kapasiteleri için Hesaplanması: İzmir Çiğli Örneği
}

\author{
Sedat Yalçınkaya ${ }^{1, *}$ \\ ${ }^{1}$ Izmir Katip Çelebi Üniversitesi, Mühendislik ve Mimarlık Fakültesi, Çevre Mühendisliği Bölümü, 35620 Çiğli, İzmir
}

\section{Özet}

Bu çalıșmada evsel katı atık toplama ve taşıma sisteminden kaynaklanan önemli hava kirleticileri (CO, $\mathrm{NMVOC,} \mathrm{NO}_{x}, \mathrm{PM}_{2} \mathrm{~N}_{2} \mathrm{O}, \mathrm{NH} \mathrm{H}_{3}$, $\mathrm{SO}_{2}$ ve $\left.\mathrm{CO}_{2}\right)$ emisyonlarinin hesaplanmast ve toplama aract kapasitesinin $\left(8+1 \mathrm{~m}^{3}\right.$ ve $\left.13+1.5 \mathrm{~m}^{3}\right)$ kirletici emisyonlarina etkisinin incelenmesi için Coğrafi Bilgi Sistemleri (CBS) tabanlı bir yöntem geliștirilmiș ve İzmir'in Çiğli ilçesi için uygulanmıștır. CBS tabanlı Vehicle Routing Problem (VRP) yöntemi ile optimum güzergahların tayini, toplam kat edilen mesafelerin ve toplam araç çalışma sürelerinin tespiti gerçekleştirilmiştir. Akabinde araç ve yakıt türüne bağlı emisyon faktörleri ve CBS analizleri sonucu elde edilen yakıt tüketiminin çarpımına dayalı hesaplama yöntemi ile emisyonlar hesaplanmıştır. Bulgular büyük araç ile toplama yapılması halinde ihtiyaç duyulan işçi ve araç sayısı azalırken toplam yakıt tüketiminin arttı̆̆ını göstermektedir. Büyük araçla toplama yapılması halinde çalıșma kapsamında değerlendirilen hava kirleticilerinin tamamının emisyonlarında küçük araca göre \%17 artıs hesaplanmıştır. Bu çalışma temel CBS bilgisi olan katı atık yönetimi planlayıcılarına optimum toplama güzergahlarının planlanması ve emisyonların hesaplanması için az veri ile uygulanabilir, basit ve hızlı bir modelleme yöntemi sunmaktadır.

$\underline{\text { Anahtar Sözcükler }}$

Katı Atık Toplama, Hava Kirletici Emisyonları, CBS, VRP, Emisyon Envanteri

\section{Calculation of Solid Waste Collection Induced Air Pollutant Emissions through Spatial Analysis for Different Vehicle Capacities: A Case Study in Cigli, Izmir}

\begin{abstract}
In this study, A Geographic Information System (GIS) based methodology was presented to calculate the emissions of solid waste collection induced important air pollutants (CO, NMVOC, $\mathrm{NO}_{x}, \mathrm{PM}, \mathrm{N}_{2} \mathrm{O}, \mathrm{NH}_{3}, \mathrm{SO}_{2}$ and $\mathrm{CO}_{2}$ ) and to analyze the effect of collection vehicle capacity $\left(8+1 \mathrm{~m}^{3}\right.$ and $\left.13+1.5 \mathrm{~m}^{3}\right)$ on pollutant emissions and the methodology was applied to the district of Cigli in Izmir. Determination of optimum routes, total distances and total vehicle driving times were calculated through GIS-based Vehicle Routing Problem (VRP) method. Afterwards, emissions were calculated through the multiplication of fuel consumptions, obtained as a result of GIS analysis, and emission factors related to vehicle and fuel type. Results show that total fuel consumption increases while the number of employees and vehicles required are reduced when large vehicles are used. Collection with the large vehicle resulted in $17 \%$ increase in all emissions compared to the small vehicle. This study provides solid waste management planners, with basic GIS knowledge, a simple and fast modeling method that can be applied with little data for planning optimal collection routes and calculating emissions.
\end{abstract}

\section{Keywords}

Solid Waste Collection, Air Pollution Emissions, GIS, VRP, Emission Inventory

\section{Giriş}

Dünya Sağlık Örgütü verilerine göre hava kirliliğinin sadece 2016 y1lında 4.2 milyon prematüre ölüme sebep olduğu tahmin edilmektedir (WHO 2018). Genel olarak kentsel hava kirliliği kardiyovasküler ve solunum yolu hastalığı, kanser ve olumsuz doğum sonuçları riskini arttırmaktadır (WHO 2018). Hava kirliliği kaynaklı ölüm ve hastalıkların başlıca sebebi çapları 10 mikrometreden (PM10) veya 2.5 (PM2.5) mikrometreden daha kü̧̈ük olan partiküler maddelere maruz kalınmasidir (WHO 2020).

Bu boyuttaki kadar küçük parçacıklar, vücudun tozlara karşı olan savunma sistemini geçerek solunum sistemine ve hatta doğrudan kana ulaşabilmektedir. Partiküler maddeler sağllğa zararlı ağır metaller ve kanserojen maddeler de içerebilirler. Ulaşım sektörü kentsel hava kirliliğinin en önemli kaynaklarından biri olması yanı sıra partiküler madde kirliliğinin de önemli ve giderek büyüyen bir kaynağıdır (WHO 2020; Mutlu 2019). 
Karayolu trafiğinin Avrupa'daki PM emisyonlarının \%30’undan ve OECD ülkelerindeki PM emisyonlarının \%50'sinden sorumlu olduğu tahmin edilmektedir (WHO 2018). Özellikle dizel motorlu araç trafiğinin Avrupa'daki büyük şehirlerde ulaşım kaynaklı $\mathrm{PM}$ ve $\mathrm{NO}_{\mathrm{x}}$ salınımlarının \%40 ila \%60'ına sebep olduğu tespit edilmiştir (Wagner ve Rutherford 2013).

Ulaşım sektörünün başlıca kaynaklarından biri olduğu sağlığa zararlı diğer bir kirletici ise yer seviyesi ozon kirliliğidir. Yer seviyesi ozon kirliliği astım gibi kronik solunum yolu hastalıklarına sebep olmaktadır. Yer seviyesi ozon kirliliğinin büyük bir kısmı azot oksitler $\left(\mathrm{NO}_{\mathrm{x}}\right)$, karbon monoksit $(\mathrm{CO})$ ve uçucu organik bileşikler (VOC'ler) atmosferde güneş ışığı, özellikle Ultraviyole (UV) spektrumu, varlığında reaksiyona girdiğinde ortaya çıkar.

Ulaşım sektörü kaynaklı hava kirliliğinin insan sağlığına doğrudan etkileri yanı sıra su kaynaklarına etkileri gibi dolaylı etkileri de olabilmektedir. Demirel ve Ateş (2018)'in Sapanca Gölü çevresinde karayolu trafiği kaynaklı hava kirleticileri emisyon envanteri çalışması neticesinde Sapanca Gölü ve gölü besleyen dereler için karayolu trafiğinin önemli bir kirletici kaynak olduğu kanısına varılmıştır. Asitleştirici kirleticiler olarak bilinen Amonyak $\left(\mathrm{NH}_{3}\right)$ ve Sülfat $\left(\mathrm{SO}_{2}\right)$ ta ulaşım sektörü kaynaklı insan sağlı̆̆ına dolaylı etkileri olan önemli hava kirleticilerdendir (EEA 2019). Asidifikasyonun etkileri yaprakların dökülmesi, ağaçların canlılığının azalması, aside duyarlı göllerde ve nehirlerde balık stoklarının azalması gibi çeşitli şekillerde ortaya çıkar.

Ulaşım sektörü sera gazı (GHG) emisyonlarının da önde gelen kaynaklarındandır. Karbondioksit $\left(\mathrm{CO}_{2}\right)$, $\mathrm{Metan}\left(\mathrm{CH}_{4}\right)$ ve Diazotmonoksit $\left(\mathrm{N}_{2} \mathrm{O}\right)$ ile dolaylı sera gazı olan metan dişı uçucu organik bileşikler (NMVOC) karayolu araçlarından salınan başlıca sera gazlarıdır (EEA 2019).

Türkiye'de ulaşım sektöründeki yolcu ve yük taşımacılığının sırasıyla \%92 ve \%95'inin karayolu ile sağlandığı (Solmaz ve Çelikten 2012) ve dizel motorlu araçların karayolu trafiği kaynaklı hava kirliliğindeki önemli payı (Wagner ve Rutherford 2013) dikkate alındığında dizel motorlu karayolu trafiği ulaşım kaynaklı hava kirliliğinin önemli etkenlerinden biri olarak değerlendirilebilir.

Yukarıda bahsi geçen kirleticilerden bazılarının ülkemizdeki ortalama konsantrasyonları ve sınır değerleri (ÇŞB 2019b) ve sera gazı salınımları (TÜİK 2018) Tablo 1'de gösterilmiştir. PM2.5 için ulusal bir sınır değerimiz mevcut değildir. Birleşmiş Milletler (BM) sınır değeri $25 \mu \mathrm{g} / \mathrm{m}^{3}$ ve WHO tavsiye edilen sınır değeri ise $10 \mu \mathrm{g} / \mathrm{m}^{3} \mathrm{olarak}$ belirlenmiştir. Ülkemizde 2018 y1lında 68 istasyonda PM2.5 ölçümü yapılmıştır. İzmir'de ise PM2.5 ölçümü yapılmamaktadır. 2018 yılında güvenli veri alımının sağlandığ 21 istasyonun tamamı (ÇMO 2018) ve 2010 - 2017 yılları arası Türkiye ortalaması dikkate alındığında WHO tarafından tavsiye edilen sınır değerin üzerinde kalınmaktadır. Aynı durum PM10 için de geçerlidir. İzmir'de ölçülen ve Türkiye ortalama PM10 konsantrasyonları 2010- 2017 yılları arasında sürekli sınır değerleri aşmıştır. Son 15 yılda Türkiye'de yapılan partiküler madde ölçümleri Avrupa'ya kıyasla hep daha yüksek sonuçlar vermiştir (ÇMO 2018). 2010 - 2017 yıları arasında yapılan ölçümlerdeki $\mathrm{SO}_{2}, \mathrm{NO}_{2}$ ve $\mathrm{CO}$ konsantrasyonları Türkiye ortalama değerleri ise ulusal ve uluslararası sınır değerlerin altında sonuçlar vermiştir. Özetle, partiküler maddeler ülkemizde ulaşım sektörünün etkili olduğu hava kirleticilerinin en önemlileridir. Dolayısıyla partiküler madde konsantrasyonlarının insan sağlığına zararlarını kabul edilebilir seviyelere (belirlenen sınır değerlerin altına) indirebilmek için alınacak önlemlere karayolu trafiği ve özellikle dizel araç trafiğinden başlanması doğru olacaktır.

Sera gazı salınımlarını inceleyecek olursak 2010 - 2016 yılları arasında sürekli artış göstermektedir. Kişi başına düşen sera gazı salınımında da artış olmuştur. 1990, 2015 ve 2016 yılları için kişi başına sera gazı miktarları sırasıyla 3.8, 6.04 ve 6.3 ton olarak hesaplanmıştır. 2016 yılında salınan sera gazlarının \%20’si ulaştırma kaynaklıdır. Ülkemizdeki 2016 yılı sera gazı salınımları alt sektörlere göre paylaştırıldığında çevirim ve enerji sektöründen (\%35.6) sonra en fazla salınım ulaşım sektöründen kaynaklanmaktadır (TÜİK 2018). Sera gazı salınımlarının azaltılması için önlem alınması gereken alanlarda da ulaşım sektörü önde gelmektedir.

Ulaşım sektörü kaynaklı hava kirliliğinin önlenmesi için yakıt teknolojilerinde iyileştirme çalışmaları, motor teknolojilerinde emisyon azaltım çalışmaları, dizel filtreleri geliştirilmesi gibi ürün geliştirmeye dayalı çözümlerin yanı sıra daha verimli ulaşım planlarının hazırlanması da tavsiye edilmektedir (US EPA 2019; Yapıcı ve Koldemir 2016). Bu çalışmada ise daha verimli ulaşım planlaması ile emisyon azaltımı için belediye atıkları toplama ve taşıma sistemi üzerine çalışılmıştır.

Ülkemizde belediye atıklarının toplanması ve taşınması ilçe belediye sınırları içerisinde ilçe belediyesi sorumluluğunda gerçekleştirilmektedir. İlçe sınırları içerisinde toplanan katı atıklar ya toplama araçları ile doğrudan düzenli depolama alanlarına taşınır ya da aktarma istasyonlarında daha büyük transfer araçlarına aktarılır. Atık kaynaklarının dağınık yapısı ve toplama alanının büyüklüğü sebeplerinden atık toplama işlemleri genellikle verimlilikten oldukça uzaktır. Güzergah planlamaları optimum değildir ve araçlar çoğu zaman kapasitelerinin altında (yarı dolu) çalışmaktadır (Yildiz vd. 2009). Belediye atıkları toplama sisteminin sürekliliği ve kullanılan araçların dizel motorlu kamyonlar olduğu dikkate alınınca ulaşım sektörü kaynaklı hava kirliliğinde önemli bir yeri olduğu tahmin edilebilir.

Belediye atığı toplama ve taşıma sisteminin optimizasyonu gidilen yolun, harcanan zamanın ve yakıtın ve dahi egzoz emisyonlarının azaltılmasına yardımcı olabilir. Literatürde atık toplama ve taşıma sistemi genellikle optimum toplama güzergahının tayinini sağlayan "Vehicle Routing Problem (VRP)" problemi olarak tanımlanmış ve çözümlenmiştir. Bazı çalışmalarda VRP matematiksel programlama yoluyla çözülmüştür (Chatzouridis ve Komilis 2012; Das ve Bhattacharyya 2015; Mantzaras ve Voudrias 2017).

Bu çalışmalarda öncelikle tüm toplama noktaları, depo sahaları ve transfer istasyonları arasındaki mesafeler Coğrafi Bilgi Sistemleri (CBS) yardımıyla tespit edilmiştir. Daha sonra hedeflenen amaç fonksiyonuna göre (mesafe, zaman, maliyet veya emisyon salınımını minimuma indirecek şekilde) optimizasyon problemi kurulmuş ve MATLAB, CPLEX vb. 
programlar veya What'sBest! gibi Excel eklentileri yardımıyla çözülmüştür. Diğer bir uygulama ise optimizasyon modelinin kurulumunun ve çözümünün tamamen CBS ortamında gerçekleştirilmesidir (Abdelli vd. 2016; Apaydin ve Gonullu 2011; Apaydin ve Gonullu 2008; Vu vd. 2019). Tüm işlemlerin tek bir CBS programında gerçekleştirilmesi, kurulan modelin üzerinde kolaylıkla değişiklikler yapılabilmesini ve sonuçların haritalandırılmasını sağladığı için ikinci yaklaşımı daha avantajlı kılmaktadır.

Tablo 1: PM2.5, PM10, $\mathrm{SO}_{2}, \mathrm{NO}_{2}, \mathrm{CO}_{2}$ için sınır değerler ve yıllık konsantrasyonları ve sera gazları yıllık emisyonları

\begin{tabular}{|c|c|c|c|c|c|c|c|c|c|c|c|c|}
\hline \multirow{2}{*}{ Kirletici } & \multicolumn{3}{|c|}{ Sınır Değerler $\left(\boldsymbol{\mu g} / \mathbf{m}^{3}\right)$} & \multirow{2}{*}{ Konum } & \multicolumn{8}{|c|}{ Yll } \\
\hline & Türkiye & $\mathbf{B M}^{1}$ & WHO $^{1}$ & & 2010 & 2011 & 2012 & 2013 & 2014 & 2015 & 2016 & 2017 \\
\hline \multirow{2}{*}{ PM2.5 } & \multirow[b]{2}{*}{ - } & \multirow{2}{*}{25} & \multirow{2}{*}{10} & $\dot{\text { İzmir }}^{2}$ & - & - & - & - & - & - & - & - \\
\hline & & & & Türkiye $^{2}$ & 35 & 38 & 19 & 27 & 30 & 27 & 25 & 26 \\
\hline \multirow{2}{*}{ PM10 } & \multirow{2}{*}{40} & \multirow{2}{*}{40} & \multirow{2}{*}{20} & İzmir & 51 & 54 & 49 & 45 & 44 & 41 & 42 & 42 \\
\hline & & & & Türkiye & 72 & 63 & 62 & 59 & 55 & 57 & 56 & 55 \\
\hline \multirow{2}{*}{$\mathrm{SO}_{2}$} & \multirow{2}{*}{20} & \multirow{2}{*}{20} & \multirow{2}{*}{20} & İzmir & 13 & 14 & 9 & 8 & 8 & 10 & 11 & 11 \\
\hline & & & & Türkiye & 16 & 20 & 17 & 19 & 18 & 17 & 15 & 13 \\
\hline \multirow{2}{*}{$\mathrm{NO}_{2}$} & \multirow{2}{*}{44} & \multirow{2}{*}{40} & \multirow{2}{*}{40} & İzmir & - & - & - & - & 21 & 7 & 3 & 26 \\
\hline & & & & Türkiye & 64 & 66 & 39 & 34 & 28 & 33 & 38 & 36 \\
\hline \multirow{2}{*}{$\mathrm{CO}$} & \multirow{2}{*}{10,000} & \multirow{2}{*}{10,000} & & İzmir & - & - & 25 & 87 & 440 & 330 & 369 & 707 \\
\hline & & & & Türkiye & 1.013 & 1.267 & 875 & 847 & 859 & 844 & 907 & 929 \\
\hline $\begin{array}{l}\text { Sera } \\
\text { gazları }\end{array}$ & \multicolumn{3}{|c|}{$\mathrm{CO}_{2}$ eşdeğeri (Milyon ton) } & Türkiye & 402.6 & 431.4 & 445.6 & 439 & 451.8 & 469.9 & 496.1 & - \\
\hline
\end{tabular}

${ }^{1}$ (EEA 2016), ${ }^{2}$ (ÇŞB 2019b)

Bu çalışmada katı atık toplama ve taşıma sisteminden kaynaklanan önemli hava kirleticileri $\left(\mathrm{CO}, \mathrm{NMVOC}, \mathrm{NO}_{\mathrm{x}}, \mathrm{PM}\right.$, $\mathrm{N}_{2} \mathrm{O}, \mathrm{NH}_{3}, \mathrm{SO}_{2}$ ve $\left.\mathrm{CO}_{2}\right)$ emisyonlarının hesaplanması ve toplama aracı kapasitesinin $\left(8+1 \mathrm{~m}^{3}\right.$ ve $\left.13+1.5 \mathrm{~m}^{3}\right) \mathrm{kirletici}$ emisyonlarına etkisinin incelenmesi için CBS tabanlı bir yöntem geliştirilmiş ve İzmir'in Çiğgi ilçesi için uygulanmıştır. $\mathrm{Bu}$ çalışmanın literatürdeki benzer çalışmalardan farkı ise az veri ile uygulanabilir, basit ve hızlı bir modelleme yöntemi sunmasidir.

\section{Materyal ve Yöntem}

Çalışma kapsamında 3 adımlı bir yöntem uygulanmıştır. Öncelikle ihtiyaç duyulan veriler uygun formatlara dönüştürülerek bir coğrafi veri tabanı oluşturulmuştur. Akabinde çalışma kapsamında değerlendirilen 2 farklı toplama aracı kapasitesi için VRP modeli kurulmuş ve çözülmüştür. Son olarak VRP modeli çıktılarından faydalanılarak Tier 1 yöntemiyle her bir araç kapasitesi için egzoz emisyon değerleri hesaplanmıştır. Yöntemin iş akım şeması Şekil 1'de gösterilmiştir. Yöntem hakkında detaylı bilgi ise makalenin devamında verilmiştir. 


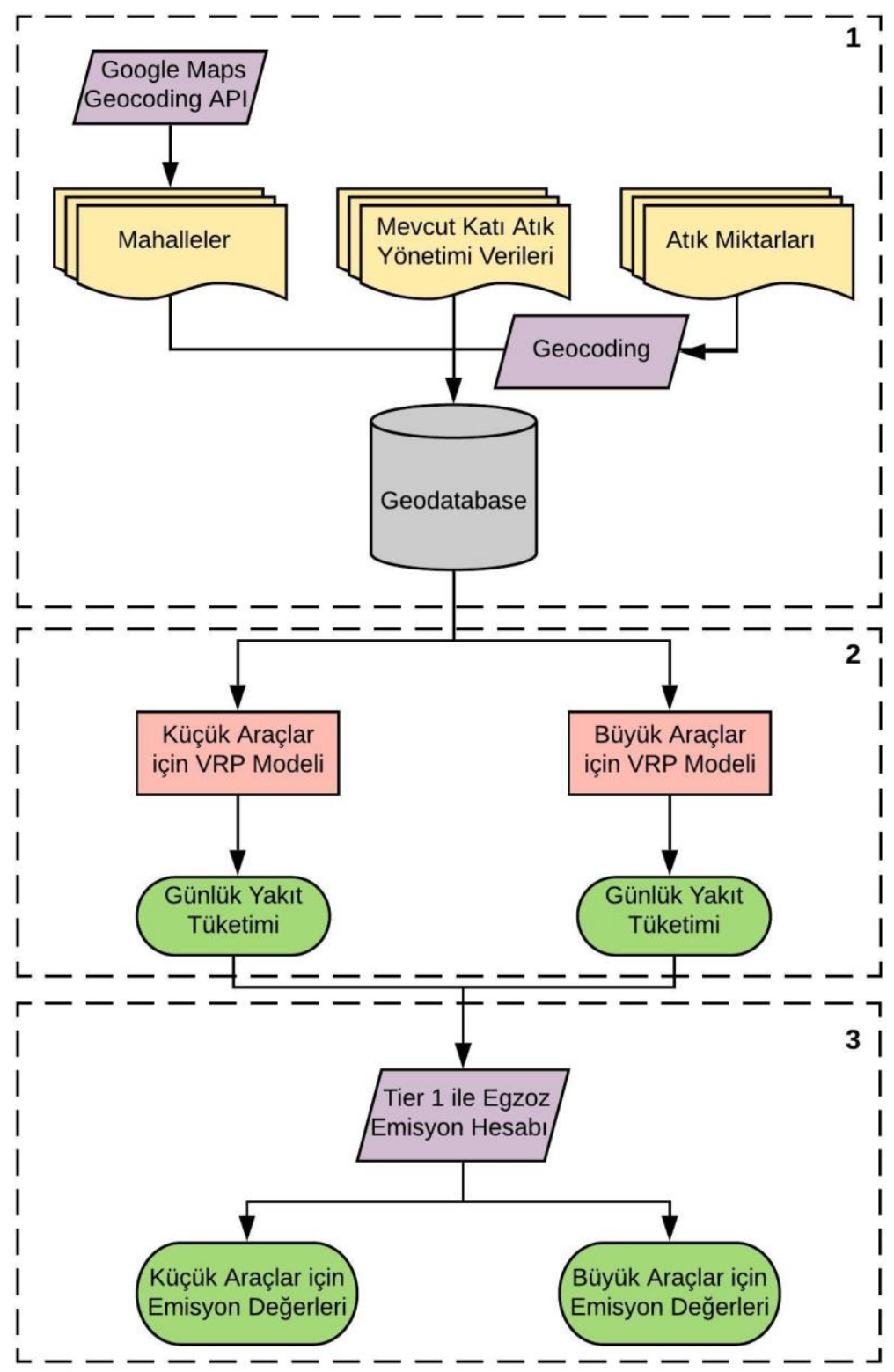

1 Coğrafi Veri Tabanı Oluşturulması

2 Vehicle Routing Problem Analizi

3 Tier 1 ile Emisyonların Hesaplanması

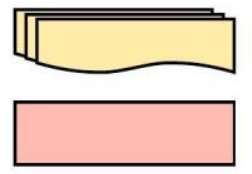

Veri

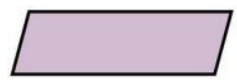

Diğer

Uygulamalar

CBS

Uygulamaları

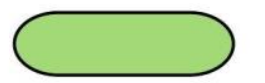

Çıktı

Şekil 1: Uygulanan yöntemin iş akım şeması

\section{1. Çalışma Alanı}

Çiğli İzmir Körfezinin kuzeyinde, Menemen ve Karşıyaka ilçeleri arasında yer alır. Nüfus olarak İzmir'in kalabalık ilçelerinden biridir. 2017 ve 2018 yılları nüfusu sırasıyla 190.607 ve 194.525 olarak belirlenmiştir (TÜIK 2019). İlçenin yüz ölçümü $134 \mathrm{~km}^{2}$ 'dir ve toplam 26 mahalleden oluşmaktadır. İlçe İzmir'in iki katı atık depo sahasından en fazla atık kabul eden depo sahası olan Harmandalı Katı Atık Depo Sahasına ev sahipliği yapmaktadır. İlçede katı atık transfer istasyonu bulunmadığından mahallelerden toplanan atıklar doğrudan Harmandalı Katı Atık Depo Sahasına taşınmaktadır. İlçenin konumu Şekil 2'de gösterilmiştir. 


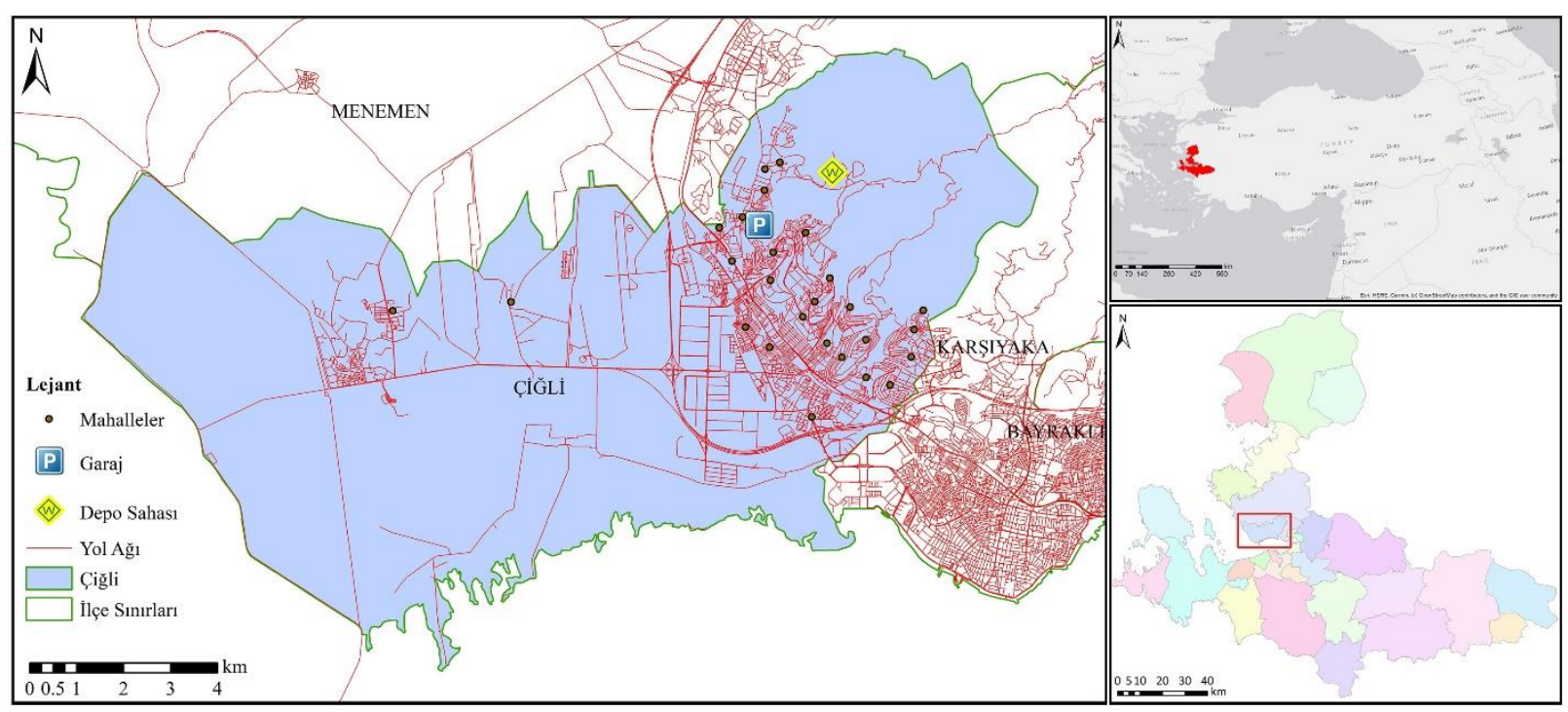

Şekil 2: Çalışma alanı, Çiğli, İzmir (Opent Street Map 2020; ESRI 2020)

\subsection{Coğrafi Veri Tabanı Oluşturulması}

Çalışmanın ilk adımı gerekli verilerin CBS ortamında (ArcGIS programı ile) uygun formatlarda (gdb, mdb, csv. vb.) düzenlenmesidir. Bu kapsamda ihtiyaç duyulan veriler: mahalle bazında yerleşim yerleri konumları (mahalle merkezleri koordinatları), katı atık toplama araçları garajı konumu, katı atık depo sahası konumu (Harmandalı Katı Atık Depo Sahası), atık üretim hızı, yol ağı, katı atık konteyneri kapasitesi, toplama aracı kapasiteleri ve birim zamandaki toplama aracı yakıt tüketim miktarları bilgileridir.

Mahalle bazında yerleşim yerleri konumları (mahalle merkezleri koordinatları) "Organik Atıkların Yönetimi için Coğrafi Bilgi Sistemleri Tabanlı Çok Kriterli Karar Destek Sistemi Oluşturulması: İzmir Örneği” isimli ve 118Y043 nolu TÜBITTAK projesi kapsamında tüm İzmir için üretilmiştir (Yalcinkaya 2020; Yalçınkaya ve Kırtıloğlu 2019). Mahalle isimlerinden coğrafi koordinatlarının üretilmesi işlemi Geocoding (coğrafi kodlama) olarak isimlendirilmektedir. Bu işlem ticari olmayan kullanımlar için belirli kısıtlamalar dışında (örn. günde 1.000 adet kodlama) ücretsiz olarak birçok çevrimiçi harita servisi tarafından (Google Maps, Bing Maps vb.) sunulmaktadır. Bu projede coğrafi kodlama işlemi için en pratik çözümü sunan Google Maps Geocoding API kullanılmıştır. İşlemin pratikliği Google tarafından sunulan ve Geocoding API hizmetini de barındıran Google Fusion Tables sayesinde gerçekleşmektedir. Süreç şu şekilde gerçekleşmektedir; öncelikle Türkiye İstatistik Kurumu (TUIKK)'ten elde edilen mahalleler listesi Google Fusion Tables servisine aktarılmıştır. Bu servisi kullanabilmek için kullanıııların bir Google hesabına sahip olması yeterlidir. Google Drive hizmetine entegre olarak kullanılabilen Fusion Tables servisi listeyi coğrafi etiket olarak değerlendirebilmekte ve Google'ın veri tabanı ile bu listeyi eşleştirip coğrafi koordinatı üretebilmektedir. Bu sayede İzmir İl sınırları içerisindeki tüm mahalle yerleşim merkezleri vektör formatında üretilmiştir. Bu veri ile diğer öznitelik bilgileri (nüfus ve belediye atığı miktarı) her bir mahalle için düzenlenmiş ve ilişkilendirilmiş̧ir. Katı atık toplama araçları garajı konumu ve katı atık depo sahası konumu (Harmandalı Katı Atık Depo Sahası) verileri ise Google Earth Pro programında kml dosyası olarak üretildikten sonra vektör formatında ArcGIS programına aktarılmıştır.

Belediye atığı miktarı nüfus ve kişi başı atık üretim hızının çarpımıyla tüm mahalleler için hesaplanmıştır. İzmir'de 2016 yılında (çalışma yapılırken elde edilen en güncel veri) üretilen kişi başı ortalama belediye atığı miktarı ise 1.32 kg/kişi-gün'dür (TUiKK 2017). Çiğli için günlük belediye atığı miktarı 251.6 ton olarak hesaplanmıştır. Kişi başı atık üretim miktarı değerleri mahallelerin sosyoekonomik yapısına göre değişim gösterir. Ancak böyle bir veri mevcut olmadığı ve bu çalışma kapsamında üretilmesi planlanmadığından tüm mahalleler için ortalama değerler kullanılmıştır.

Analizlerde kullanılacak yol ağı verisi OpenStreetMap (OSM 2020) kaynağından temin edilmiştir. İzmir il sınırları içerisindeki güncel yol ağı verisi, bu veri seti içerisinden SQL (Structured Query Language) söz dizimleri ile filtrelenerek sadece yol ağı verisi kalacak şekilde sadeleştirilmiş̧ir. Ancak bu veri içerisinde OSM yol sınıflandırmasındaki tüm vektörel veri sınıfları bulunmaktadır. Analizlerde kullanılmayacak yol sınıfları elenmiştir (örn, bisiklet yolları, yaya yolları, vb.).

Daha sonra Karayolları Genel Müdürlüğü tarafından kamyonlar (N2-N3 araç cinsi) için belirlenen yasal hız sınırları yol sınıfina göre öznitelik tablosuna eklenmiştir. Akabinde seyahat süreleri de eklenerek hem mesafe hem de seyahat süresine göre analiz yapabilecek şekilde yol ağı (network dataset) hazırlanmıştır. Konteyner kapasiteleri ve araç kapasiteleri Kamu İhale Kurumu'nun Elektronik Kamu Alımları Platformu üzerinden sorgulanmış ve en güncel ihale verileri kullanılarak belirlenmiştir. Konteyner kapasitesi $770 \mathrm{~L}$ olarak tüm ilçe genelinde sabit kabul edilmiştir. İncelenen ihale şartnamelerinde toplama araçları kapasiteleri $7+1 \mathrm{~m}^{3}, 8+1 \mathrm{~m}^{3}, 11+1.5 \mathrm{~m}^{3}, 13+1.5 \mathrm{~m}^{3}$ gibi değişik kapasitelerde olabilmektedir. 
$\mathrm{Bu}$ çalışmada ise ihalelerde en çok talep edilen $8+1 \mathrm{~m}^{3}$ ve en fazla kapasiteye sahip $13+1.5 \mathrm{~m}^{3}$ olmak üzere iki araç kapasitesi kullanılmıştır. Araçlar 1/3 oranında hidrolik sıkıştırma gerçekleştirebilmektedir (Şahlan Makina A.Ş. 2019). $8+1 \mathrm{~m}^{3}$ kapasiteli aracın maksimum yükleme kapasitesi 5.4 ton iken $13+1.5 \mathrm{~m}^{3}$ kapasiteli aracın maksimum yükleme kapasitesi 12 tondur. Analizlerde ise maksimum araç kapasiteleri sırasıyla 5 ve 11 ton olarak alınmıştır. Ortalama evsel katı atık yoğunluğunun $440.8 \mathrm{~kg} / \mathrm{m}^{3}$ (Tchobanoglous ve Kreith 2002) olduğu dikkate alınırsa analizlerde kullanılan ton cinsinde kapasitelerin tamamının kullanılması halinde dahi yükleme hacmi aşılmamaktadır. Konteyner konumları bilgisi mevcut olmadığı için atık üretim miktarı esaslı konteyner sayıları ve konteynerlerde toplanacak atık miktarları mahalle düzeyinde belirlenip ihtiyaç duyulan konteyner sayısı kadar toplama noktası her bir mahalle merkezine noktasal vektör veri olarak eklenmiştir. Konteyner verileri VRP modelinin kurulum aşamasında toplama noktaları (Orders) olarak tanımlanmıştır. Toplama araçları birim yakıt tüketimi ise Çevre ve Şehircilik Bakanlığı’nın İnşaat Genel Fiyat Analizleri 2019 dokümanında belirtilen denklem (Denklem 1) kullanılarak hesaplanmıştır (ÇŞB 2019a). 8+1 $\mathrm{m}^{3}$ kapasiteli aracın beygir gücü 206 HP (Iveco Euro Cargo 100E19) ve 13+1.5 $\mathrm{m}^{3}$ kapasiteli aracın beygir gücü $316 \mathrm{HP}$ (Mercedes Benz Arocs $2032 \mathrm{~K}$ ) olarak kabul edilmiştir.

Yakıt (mazot) tüketimi $(\mathrm{kg} /$ saat) $=0.150 \times$ Beygir Gücü $x 0.57$

\subsection{Vehicle Routing Problem Model Kurulumu}

Toplama aracı kapasitesinin katı atık toplama ve taşıma sisteminden kaynaklanan hava kirletici emisyonlarına etkisini incelemek için $8+1 \mathrm{~m}^{3}$ veya $13+1.5 \mathrm{~m}^{3}$ kapasiteli toplama araçlarının kullanıldığı iki senaryo geliştirilmiştir. Tüm mahallelerden her gün atık toplamanın gerçekleştirildiği ve sadece evsel atıkların toplandığı (sanayi, ticari ve kurumsal atıklar ihmal edilmiştir) varsayılmıştır. Her bir senaryo (toplama aracı kapasitesi) için ArcGIS’in VRP uygulamasıyla optimum güzergah tayini gerçekleştirilmiştir.

VRP'nin temel amacı bir başlangıç noktasından başlayarak bir dizi müşteriye uğradıktan sonra belirtilen bitiş noktasına minimum maliyetle varmak için gerekli güzergah optimizasyonunun yapılmasıdır (Hannan vd. 2018). Bunu gerçekleştiren ara duraklar, araç kapasitesi ve mesai süresi gibi özelliklerde modele tanımlanabilir (Vu vd. 2019). Maliyetten kasıt ise tercihe bağlı olarak minimum zaman, mesafe veya egzoz emisyonu olabilir. Bu çalışmada kurulan modelin amacı ise aşağıdaki kısıtlamalar ile toplam zamanı (dolayısıyla yakıt tüketimi ve egzoz emisyonlarını) en aza indiren optimum rotaların belirlenmesidir.

- Tüm araçlar garajdan yola çıkar ve garajda mesailerini tamamlar.

- Atık konteyneri her seferinde sadece bir araç tarafindan toplanır.

- Bir aracın maksimum toplama kapasitesi aşılmamalıdır.

Tablo 2: Vehicle Routing Problem model girdileri

\begin{tabular}{|c|c|c|}
\hline & Senaryo $1-8+1 \mathrm{~m}^{3}$ & Senaryo $2-13+1.5 \mathrm{~m}^{3}$ \\
\hline Toplama noktaları & 754 adet & 754 adet \\
\hline Konteyner boşaltma ve konteynerler arası geçen süre ${ }^{1}$ & $5 \mathrm{dk}$ & $5 \mathrm{dk}$ \\
\hline Araç kapasitesi & $5,000 \mathrm{~kg}$ & $11,000 \mathrm{~kg}$ \\
\hline Mesai saatleri & $8: 00-17: 00$ & $8: 00-17: 00$ \\
\hline Toplam çalışma süresi & $480 \mathrm{dk}$. & $480 \mathrm{dk}$. \\
\hline İşe başlarken garajda geçen süre & $30 \mathrm{dk}$. & $30 \mathrm{dk}$. \\
\hline İş bitiminde garajda geçen süre & $30 \mathrm{dk}$. & $30 \mathrm{dk}$. \\
\hline Depo sahasında geçen süre ${ }^{2}$ & $30 \mathrm{dk}$. & $30 \mathrm{dk}$. \\
\hline \multicolumn{3}{|l|}{ Yol ağı } \\
\hline \multicolumn{3}{|l|}{ Garaj konumu } \\
\hline Harmandalı Katı Atık Depo Sahası konumu & & \\
\hline
\end{tabular}

Yol ağı (network dataset), toplama noktaları (26 mahalle merkezinde toplam 754 adet konteyner), konteynerlerdeki atık miktarı, konteyner boşaltma ve konteynerler arası geçen süre ( $5 \mathrm{dk}$, (Chatzouridis ve Komilis 2012)), araç kapasitesi $(5.000 \mathrm{~kg}$ veya $11.000 \mathrm{~kg}$ ), işe başlama ve bitiş saatleri (time window 8:00 - 17:00), günlük toplam çalışma süresi (480 $\mathrm{dk}$ ), işe başlarken ve iş bitiminde garajda geçirilen süre (her biri için $30 \mathrm{dk}$ ), depo sahasında geçen süre (30 dk, (Komilis 2008), garaj konumu ve katı atık depo sahası konumu modele girdi olarak tanıtılmıştır (Tablo 2). Toplama zamanını minimuma indirecek şekilde amaç fonksiyonu seçilmiş ve model kurulumu tamamlanmıştır. 


\subsection{Model Sonuçlarının Kıyaslanması}

Toplama aracı kapasitesinin katı atık toplama ve taşıma sisteminden kaynaklanan önemli hava kirletici emisyonlarına etkisini incelemek için güzergah/mesai sayıları, toplama aracı seyahat mesafeleri, toplama aracı çalışma süreleri ve hava kirletici emisyonları kıyaslanmıştır. Her bir senaryo için VRP modelinin çözülmesi ile optimum toplama güzergahları, mesai sayıları, toplama aracı seyahat mesafeleri ve toplama aracı çalışma süreleri belirlenmiştir. Hava kirletici emisyonlarının hesabında Avrupa Çevre Ajansı'nın Hava Kirletici Emisyon Envanteri Rehber Dokümanında belirtilen 1 numaralı yöntem (Tier 1) uygulanmıştır (EEA 2019). Tier 1 araç ve yakıt türüne bağlı ortalama emisyon faktörleri ile yakıt tüketiminin çarpımına dayalı bir hesaplama yöntemi sunmaktadır. Tier 1 yöntemiyle egzoz emisyon hesapları Denklem 2 ile gösterilmiştir.

$$
E_{i}=\sum_{j}\left(\sum_{m}\left(F C_{j, m} \times E F_{i, j, m}\right)\right)
$$

Denklem 2'de $E_{\mathrm{i}}$ : i kirleticisi emisyonunu (g), $\mathrm{FC}_{\mathrm{j}, \mathrm{m}}$ : $\mathrm{m}$ türü yakıt kullanan j sınıfı araç kategorisi için yakıt tüketimi (kg) ve $\mathrm{Ef}_{\mathrm{i}, \mathrm{j}, \mathrm{m}}$ : $\mathrm{m}$ türü yakıt ve j sınıfı araç kategorisi için yakıt tüketimi esaslı emisyon faktörünü ifade etmektedir. Araç sinıfları yolcu, hafif ticari $(<3.5 \mathrm{t}$ ), ağır araçlar $(>3.5 \mathrm{t})$ ve L-kategorisi (motosiklet ve ATV gibi küçük araçlar) olmak üzere 4 sınıfa ayrılmıştır. Yakıt türleri ise benzin, dizel, LPG ve doğalgaz olarak sınıflandırılmıştır. Katı atık toplama araçları dizel motorlu ağır araçlar sınıfina girmektedir. Dizel motorlu ağır araçlar için belirlenen emisyon faktörleri Tablo 3'te gösterilmiştir. Tablo 3'teki maksimum değerlerin tespitinde eski ve emisyon kontrolü ihmal edilerek üretilmiş araç teknolojileri esas alınmıştır. Minimum değerler ise 2005 yılı Avrupa ortalama değerleri esas alınarak tespit edilmiştir.

Tablo 3: Dizel motorlu ağır araçlar için emisyon faktörleri (EEA 2019)

\begin{tabular}{|l|c|c|c|}
\hline \multirow{2}{*}{ Kirleticiler } & \multicolumn{3}{|c|}{ Faktörler (g/kg yakit) } \\
\cline { 2 - 4 } & Ortalama & Asgari & Azami \\
\hline $\mathrm{CO}$ & 7.58 & 5.73 & 10.57 \\
\hline $\mathrm{NMVOC}$ & 1.92 & 1.33 & 3.77 \\
\hline $\mathrm{NO}_{x}$ & 33.37 & 28.34 & 38.29 \\
\hline $\mathrm{PM}$ & 0.94 & 0.61 & 1.57 \\
\hline $\mathrm{N}_{2} \mathrm{O}$ & 0.051 & 0.03 & 0.089 \\
\hline $\mathrm{NH}_{3}$ & 0.013 & 0.01 & 0.018 \\
\hline $\mathrm{SO}_{2}$ & 0.006 & - & - \\
\hline $\mathrm{CO}_{2}$ & 3.169 & - & - \\
\hline
\end{tabular}

\section{Bulgular ve Tartışma}

Mahallelerin atık üretim hızı arttıkça büyüyen semboller ve güzergahların ise farklı renkte çizgiler ile gösterildiği optimum güzergah sonuçları Şekil 3'te gösterilmiştir. Aynı renkli çizgiler Bölüm 2.2'de belirtilen özelliklerde bir toplama sistemi için bir mesai süresi içerisinde yapılabilecek optimum güzergahı göstermektedir. Aynı yolu kullanan güzergahların üst üste binmesini önlemek ve gidilen mahalleleri daha net gösterebilmek için güzergahlar düz çizgiler ile gösterilmiştir. VRP ile güzergah hesabında ise gerçek yol ağı kullanılmıştır. Çalışma kapsamında atık toplamanın modellendiği yerleşim yerleri ağırlıklı olarak ilçenin doğusunda yer almaktadır. İlçenin batısında yer alan Sasalı ve Kalkıç mahalleleri ise diğer mahallelere, garaja ve depo sahasına daha uzaktadırlar. Ayrıca bu mahallelerde üretilen evsel atıklar diğer mahallelere nazaran daha azdır. 


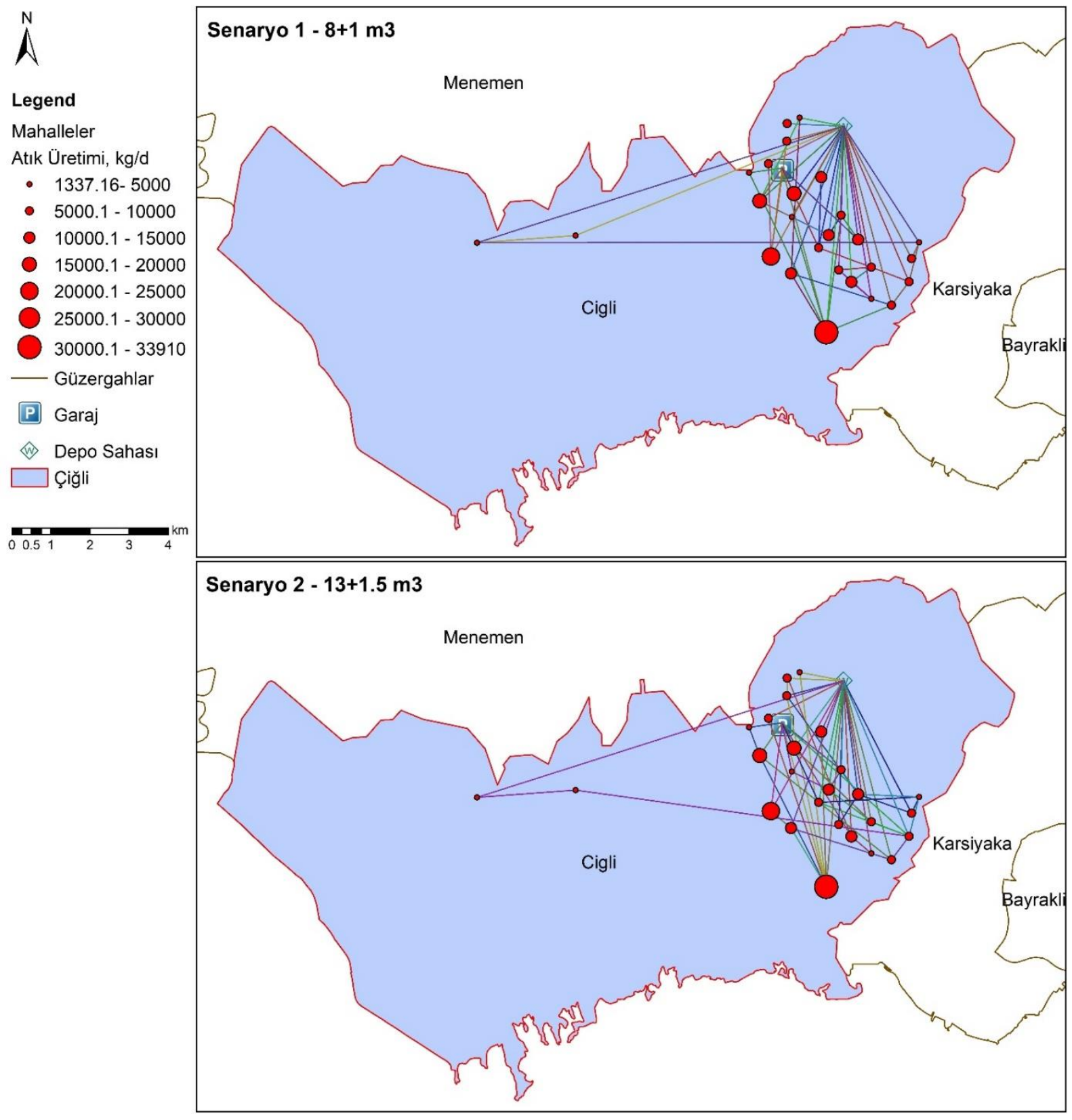

Şekil 3: Atık üretim miktarları ve optimum güzergahlar

Senaryo 1'de modellenen $8+1 \mathrm{~m}^{3}$ 'lük araç ile ilçedeki tüm atıkları toplamak için her biri 8 saatlik çalışma mesaisine denk gelen 17 optimum güzergah hesaplanmıştır (Tablo 4). Senaryo 2'de modellenen 13+1.5 m³'lük araç için ise 13 güzergah hesaplanmıştır. Araç kapasitesi artınca ihtiyaç duyulan mesai sayısında \%24 azalma hesaplanmıştır. Güzergah başına kat edilen mesafe ise daha yüksek kapasiteli araç için \%26 oranında az hesaplanmıştır. Küçük araç ile bir mesai süresi içinde ortalama 3 defa depo sahasında döküm yapılırken büyük araç ile 2 defa döküm yapılması yeterli olmaktadır.

Küçük araçlar ile bir mesai süresinde ortalama 44 konteyner toplanırken büyük araç ile 58 konteyner toplanabilmektedir. Küçük araçlar için günlük toplam çalışma süresi \%24 daha fazla iken yakıt tüketimi \%17 daha az hesaplanmıştır. Araç çalışma süresinin fazla olup yakıt tüketiminin daha az olmasının nedeni küçük araçların beygir gücünün daha az olmasından kaynaklanmaktadır.

Emisyon miktarı yakıt tüketimi ile pozitif lineer ilişkiye sahip olduğu için Senaryo 2 ile modellenen $13+1.5 \mathrm{~m}^{3}$ kapasiteli büyük toplama araçları ile katı atıkların toplanması halinde çalışma kapsamında değerlendirilen tüm kirleticilerde \%17 oranında daha fazla emisyon hesaplanmıştır (Şekil 4). Şekil 4'te her bir kirletici için hesaplanan ortalama emisyon değerleri bar grafik olarak gösterilmiştir. Minimum ve maksimum emisyon değerleri ise çubuklar ile gösterilmiştir. Kirletici parametrelerin her bir senaryo için günlük kütlesel emisyon değerleri Şekil 3 'te grafiklerin altında tablo formatında gösterilmiştir. Tier 1 ile hesaplanan nihai emisyon değerleri yeni araç filoları (Euro 2 ve daha sonrası motor tipine sahip araçlar) için daha yüksek sonuçlar verebilmektedir. 
Çiğli ilçesindeki katı atık toplama araç filosunun genellikle Euro 6 gibi daha yeni motor teknolojilerine sahip araçlardan oluştuğu göz önüne alınırsa çalışma sonucunda elde edilen sonuçların gerçek değerlerden biraz daha yüksek olabileceği tahmin edilmektedir.

Tablo 4: VRP model sonuçları

\begin{tabular}{|l|c|c|c|}
\cline { 2 - 4 } \multicolumn{1}{c|}{} & $\begin{array}{c}\text { Senaryo 1 - } \\
\mathbf{8 + 1} \mathbf{~ m}^{\mathbf{3}}\end{array}$ & $\begin{array}{c}\text { Senaryo 2 - } \\
\mathbf{1 3 + 1 . 5} \mathbf{~ m}^{\mathbf{3}}\end{array}$ & Değişim \\
\hline Güzergah (mesai) sayısı & 17 & 13 & $-24 \%$ \\
\hline Ortalama toplanan konteyner sayısı (konteyner/güzergah) & 44 & 58 & $31 \%$ \\
\hline Ortalama mesai süresi (saat/güzergah) & 450 & 447 & $-1 \%$ \\
\hline Ortalama kat edilen mesafe (m/güzergah) & 52,248 & 38,485 & $-26 \%$ \\
\hline Ortalama araç boşaltım sayısı (adet/güzergah) & 3 & 2 & $-33 \%$ \\
\hline Toplam araç çalışma süresi (dk/gün) & 6,626 & 5,028 & $-24 \%$ \\
\hline Toplam yakıt tüketimi (kg/gün) & 1,934 & 2,264 & $17 \%$ \\
\hline
\end{tabular}

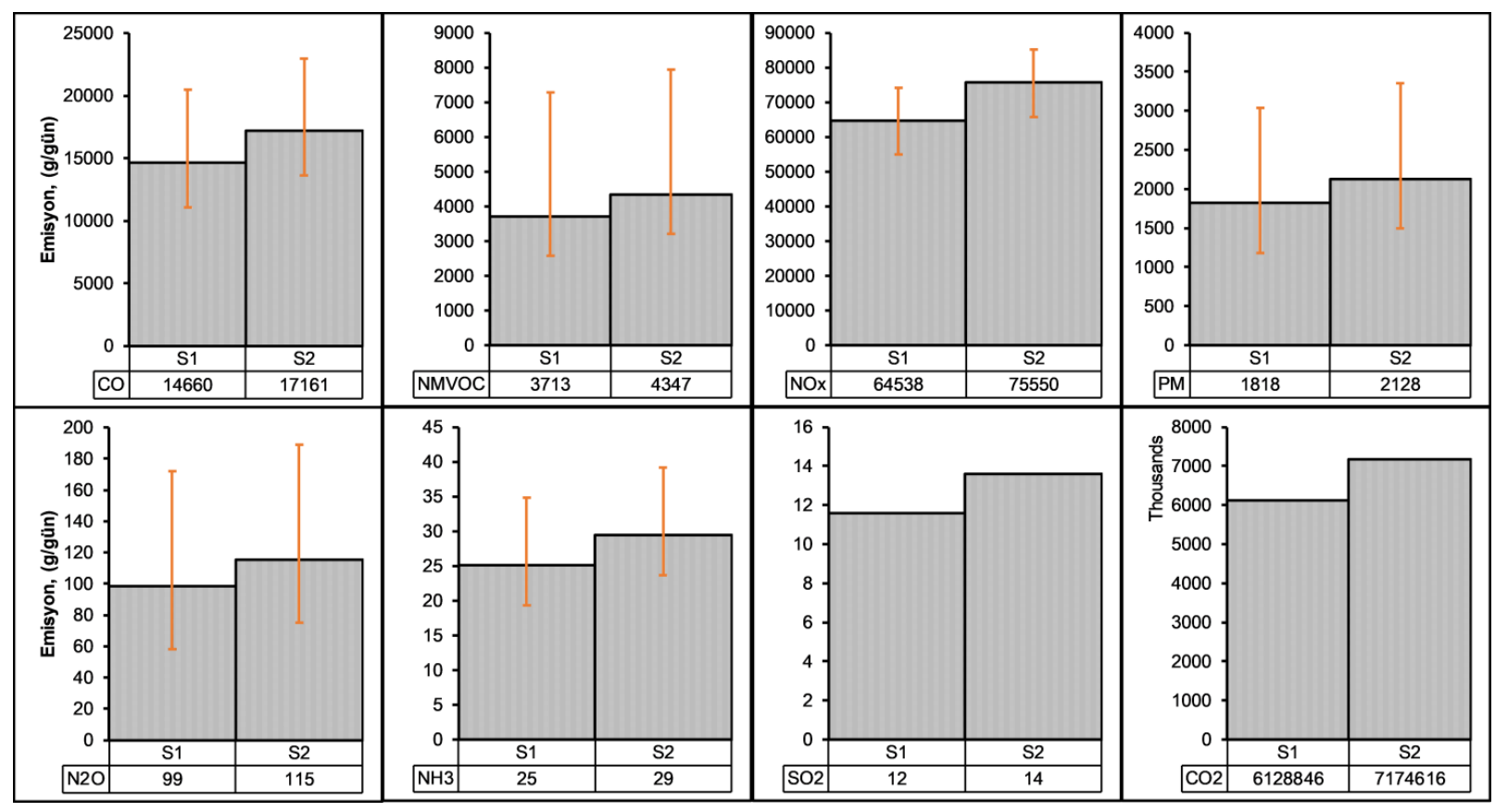

Şekil 4: Senaryo $1-8+1 \mathrm{~m}^{3}$ (S1) ve Senaryo $2-13+1.5 \mathrm{~m}^{3}$ (S2) için emisyon sonuçları

Çalışma sonucu hesaplanan emisyon değerleri ve 2019 yılı Türkiye Emisyon Bilgilendirme Raporu (Turkey’s Informative Inventory Report, IIR) Ek 1 'inde ulaşım sektörü ve ağır araçlar ve otobüsler alt sektörü (1A3biii) için belirtilen 2018 yılı emisyon değerleri Tablo 5'te sunulmuştur. Türkiye BM Uzun Mesafeli Sınır Ötesi Hava Kirliliği Kongresi ve Avrupa İzleme ve Değerlendirme Programı (EMEP) Protokolü gereğince 2011 yılından beri ulusal hava kirleticileri emisyon envanteri bilgilerini yıllık olarak raporlamaktadır. Emisyon envanteri çok çeşitli sektörler ve alt sektörleri için $\mathrm{NO}_{\mathrm{x}}, \mathrm{NMVOC}, \mathrm{SO}_{2}, \mathrm{NH}_{3}, \mathrm{CO}$ ve PM10 kirleticileri için düzenlenmektedir.

Tablo 5'te çalışma sonuçlarının her bir kirletici için 2018 yılı ulusal toplam emisyon değerine oranı belirtilmiştir. En yüksek oran amonyak $\left(\mathrm{NH}_{3}\right)$ için ve en düşük oran ise sülfat $\left(\mathrm{SO}_{2}\right)$ için hesaplanmıştır. Tüm kirleticilerin ortalama emisyon değerleri ise Senaryo 1 için \%0.023'e ve Senaryo 2 için \%0.027'ye tekabül etmektedir. Çiğli nüfusunun Türkiye geneline oranı (\%0.24) esas alınarak çalışma sonuçlarının 2018 yılı ulusal emisyon değerlerine oranı değerlendirildiğinde nüfus oranının emisyon oranından 10 kat daha fazla olduğu görülmektedir. Bu farkın ulusal emisyon değerlerinin hesabında mevcut çalıșmadan farklı olarak tüm ağır vasıta karayolu araçları ve otobüslerin dikkate alınmasından kaynaklandığı düşünülebilir. 
Tablo 5: Çalışma sonuçları ve 2017 yılı Türkiye ulusal emisyon değerlerinin karşılaştırılması (MEU 2019)

\begin{tabular}{|c|c|c|c|c|c|}
\hline \multirow{2}{*}{ Emisyonlar } & \multirow{2}{*}{$\begin{array}{l}\text { Senaryo } 1- \\
8+1 \mathrm{~m}^{3}\end{array}$} & \multirow{2}{*}{$\begin{array}{l}\text { Senaryo } 2 \text { - } \\
13+1.5 \mathrm{~m}^{3}\end{array}$} & \multirow{2}{*}{$\begin{array}{c}\text { Ulusal Toplam } \\
\text { (2018) }\end{array}$} & \multicolumn{2}{|c|}{ Oranlar } \\
\hline & & & & Senaryo 1 & Senaryo 2 \\
\hline CO (g/gün) & 14,660 & 17,161 & $64,993,667$ & $0.023 \%$ & $0.026 \%$ \\
\hline NMVOC (g/gün) & 3,713 & 4,347 & $18,211,891$ & $0.020 \%$ & $0.024 \%$ \\
\hline $\mathrm{NO}_{\mathrm{x}}(\mathrm{g} /$ gün$)$ & 64,538 & 75,550 & $229,829,509$ & $0.028 \%$ & $0.033 \%$ \\
\hline PM (g/gün) & 1,818 & 2,128 & $8,469,933$ & $0.021 \%$ & $0.025 \%$ \\
\hline $\mathrm{NH}_{3}$ (g/gün) & 25 & 29 & 71,452 & $0.035 \%$ & $0.041 \%$ \\
\hline $\mathrm{SO}_{2}$ (g/gün) & 12 & 14 & 87,836 & $0.013 \%$ & $0.015 \%$ \\
\hline
\end{tabular}

Çalışma sonuçları güncel literatür ile kıyaslandığında oldukça benzer sonuçlar tespit edilmiştir. Örneğin, Molina vd. (2019) İspanya'nın 72,800 nüfuslu Alcalá de Guadaíra Belediyesi için katı atık toplama ve taşıma sisteminden kaynaklanan $\mathrm{CO}_{2}, \mathrm{NO}_{x}$, NMVOC ve PM emisyonlarını hesaplamışlardır. Euro 3 motor teknolojisine sahip araç fílosundan oluşan mevcut katı atık toplama ve taşıma sisteminden kaynaklanan hava kirletici emisyonlarının modellenmesi için COPERT modeli uygulanmıştır. Molina vd. (2019) tarafından hesaplanan emisyonlar tüketilen yakıt miktarına bölünerek yakıt tüketimine bağlı emisyon faktörleri (g emisyon/km yakıt) hesaplanmış ve bu çalışmada kullanılan ortalama emisyon faktörleri ile karşılaştırılmıştır (Tablo 6). Bu çalışmada kullanılan ve Molina vd. (2019) çalışmasından türetilen emisyon faktörleri sırasıyla $\mathrm{CO}_{2}$ için 3.169 ve $3.142 \mathrm{~g} / \mathrm{kg}$ yakıt, $\mathrm{NO}_{\mathrm{x}}$ için 33.37 ve $29.90 \mathrm{~g} / \mathrm{kg}$ yakıt, NMVOC için 1.92 ve 2.11 ve son olarak PM için 0.84 ve 0.83 olarak tespit edilmiştir. Kıyaslanan çalışmalarda uygulanan yöntemlerin ve modellenen sistemlerin benzerliği dikkate alınarak sonuçlar değerlendirildiğinde iki çalışmanın da birbiriyle uyumlu sonuçlar verdiği söylenebilir.

Tablo 6: Çalışma kapsamında kullanılan ve Molina vd. (2019) çalışmasından türetilen emisyon faktörlerinin ( $g$ emisyon/kg yakıt) kıyaslanması

\begin{tabular}{|l|c|c|c|c|}
\cline { 2 - 5 } \multicolumn{1}{c|}{} & $\mathbf{C O}_{2}$ & NO $_{\mathbf{x}}$ & NMVOC & PM \\
\hline Mevcut çalışma, (g emisyon/kg yakıt) & 3.169 & 33.37 & 1.92 & 0.84 \\
\hline Molina vd. (2019), (g emisyon/kg yakıt) & 3.142 & 29.90 & 2.11 & 0.83 \\
\hline
\end{tabular}

\section{Sonuçlar}

Belediye atıkları toplama ve taşıma sisteminin sürekliliği ve kullanılan araçların dizel motorlu kamyonlar olduğu dikkate alınınca ulaşım sektörü kaynaklı hava kirliliğinde önemli bir yeri olduğu tahmin edilebilir. Belediye atı̆̆1 toplama sisteminin optmizasyonu gidilen yolun, harcanan zamanın ve yakıtın ve dahi egzoz emisyonlarının azaltılmasına yardımcı olabilir. Bu amaç doğrultusunda katı atık toplama ve taşıma sisteminden kaynaklanan hava kirletici emisyonlarının hesabında CBS tabanlı güzergah optimizasyonu uygulanmış ve toplama aracı kapasitesinin hava kirletici emisyonlarına etkisi $8+1 \mathrm{~m}^{3}$ ve $13+1.5 \mathrm{~m}^{3}$ lük araç kapasiteleri için incelenmiştir.

Bulgular büyük araç ile toplama yapılması halinde ihtiyaç duyulan işçi ve araç sayısı azalırken toplam yakıt tüketiminin arttığını göstermektedir. Büyük araçla toplama yapılması halinde çalışma kapsamında değerlendirilen hava kirleticilerinin emisyonlarında küçük araca göre \%17 artış hesaplanmıştır. Bu durumda ekonomik faktörlere göre mi yoksa emisyon azaltımı gibi çevresel faktörlere göre mi tercih yapılacağı karar vericilerin tercihine kalmaktadır.

Bu çalışma temel CBS bilgisi olan katı atık yönetimi planlayıcılarına optimum toplama güzergahlarının planlanması ve emisyonların hesaplanması için az veri ile uygulanabilir, basit ve hızlı bir modelleme yöntemi sunmaktadır. Güzergah optimizasyonunun ve sonuçların haritalandırılmasın tek bir programda gerçekleştirilmesi ve kurulan model üzerinde değişikliklerin kolaylıkla uygulanabilmesi bakımından CBS uygun bir platform olarak değerlendirilmiştir. CBS ile optimum güzergah tayini, toplam kat edilen mesafelerin ve toplam araç çalışma sürelerinin tespiti kolaylıkla gerçekleştirilmiştir. Akabinde araç ve yakıt türüne bağlı emisyon faktörleri ve CBS analizleri sonucu elde edilen yakıt tüketiminin çarpımına dayalı hesaplama yöntemi ile emisyonlar hesaplanmıştır.

Konteyner konumları, mevcut veya tercih edilen toplama sıklıkları, daha detaylı mekansal atık üretim bilgisi, toplama aracı motor teknolojisi ve yol trafik bilgileri gibi katı atık toplama ve taşıma sistemi hakkında detaylı verinin mevcut olması halinde ise VRP modeli gerçeğe daha yakın bir şekilde kurulabilir ve 2 veya 3 numaralı (Tier 2 veya Tier 3) emisyon hesap yöntemleri uygulanabilir. Böylelikle bu çalışmada sunulan CBS tabanlı modelleme yöntemi geliştirilebilir ve daha gerçekçi sonuçlar elde edilebilir. 


\section{Kaynaklar}

Abdelli I.S., Abdelmalek, F., Djelloul A., Mesghouni K., Addou A., (2016), GIS-Based Approach for Optimised Collection of Household Waste in Mostaganem City (Western Algeria), Waste Management and Research, 34(5), 417-26.

Apaydin O., Gonullu M.T., (2011), Route Time Estimation of Solid Waste Collection Vehicles Based on Population Density, Global Nest Journal, 13(2), 162-69.

Apaydin O., Gonullu M.T., (2008), Emission Control with Route Optimization in Solid Waste Collection Process: A Case Study Sadhana - Academy Proceedings in Engineering Sciences, 33(2), 71-82.

Chatzouridis C., Komilis D., (2012), A Methodology to Optimally Site and Design Municipal Solid Waste Transfer Stations Using Binary Programming, Resources, Conservation and Recycling, 60, 89-98.

ÇMO, (2018), Hava Kirliliği Raporu 2018, TMMOB Çevre Mühendisleri Odas1, Ankara, http://cmo.org.tr/resimler/ekler/ 9d62b3a2bb620a4_ek.pdf, [Erişim 24 Şubat 2020].

ÇŞB, (2019a), 2019 Yılı İnşaat Genel Fiyat Analizleri, Çevre ve Şehircilik Bakanlı̆̆ı, https://webdosya.csb.gov.tr/db/yfk/icerikler/ insaat-fiyat-analizleri-2019-turkce.pdf, [Erişim 24 Şubat 2020].

ÇŞB, (2019b), Çevresel Göstergeler, Çevre ve Şehircilik Bakanlığı, https://cevreselgostergeler.csb.gov.tr/hava-kalitesinde-pm10-veso2-ortalamalari-i-85734, [Erişim 24 Şubat 2020].

Das S., Bhattacharyya B.K., (2015), Optimization of Municipal Solid Waste Collection and Transportation Routes, Waste Management, 43, 9-18.

Demirel H., Ateş A., (2018), Sapanca Havzasında Karayolu Trafiğinden Kaynaklanan Hava Kirleticilerinin Emisyon Envanteri, Sakarya Üniversitesi Fen Bilimleri Enstitüsü Dergisi, 22(2), 150-158.

EPA, (2016), Air Quality Standards under the Air Quality Directive, and WHO Air Quality Guidelines, European Environment Agency https://www.eea.europa.eu/data-and-maps/figures/air-quality-standards-under-the, [Erişim 12 Aralık 2019].

EPA, (2019), EMEP/EEA air pollutant emission inventory guidebook 2019, European Environment Agency, https://www.eea.europa.eu/publications/emep-eea-guidebook-2019, [Erişim 24 Şubat 2020].

ESRI, (2020), Basemaps and Imagery | Digital Map Solutions, https://www.esri.com/en-us/arcgis/products/data-locationservices/data/basemaps-imagery\#image 1, [Erişim 24 Aralık 2019].

Hannan M.A., Akhtar M., Begum R.A., Basri H., Hussain A., Scavino E., (2018), Capacitated Vehicle-Routing Problem Model for Scheduled Solid Waste Collection and Route Optimization Using PSO Algorithm, Waste Management, 71, 31-41.

Komilis D., (2008), Conceptual Modeling to Optimize the Haul and Transfer of Municipal Solid Waste, Waste Management, 28(11), 2355-2365.

Mantzaras G., Voudrias E.A., (2017), An Optimization Model for Collection, Haul, Transfer, Treatment and Disposal of Infectious Medical Waste: Application to a Greek Region, Waste Management, 69, 518-534.

MEU, (2019), Turkey's Informative Inventory Report (IIR) 2019, Ministry of Environment and Urbanization, Ankara, Turkey.

Molina J.C., Eguia I., Racero J., (2019), Reducing Pollutant Emissions in a Waste Collection Vehicle Routing Problem Using a Variable Neighborhood Tabu Search Algorithm: A Case Study, TOP, 27, 253-287.

Mutlu A., (2019), Balıkesir Şehir Merkezinde Trafik Kaynaklı Hava Kirliliği Seviyelerinin Analizi, Balıkesir Üniversitesi Fen Bilimleri Enstitüsü Dergisi, 21(1), 152-168.

OSM, (2020), OpenStreetMap, https://www.openstreetmap.org/\#map=6/39.031/35.252, [Erişim 4 Kasım 2019].

Şahlan Makina A.Ş., (2019), 7+1 ve 8+1 Hidrolik Slkıştırmalı Çöp Kasası, https://www.hidroticaret.com/71-ve-81-hidroliksikistirmali-cop-kasasi-pmu1660, [Erişim 6 Ocak 2020].

Solmaz H., Çelikten İ., (2012), Estimation of Amount of Pollutants Generated by Vehicles in Turkey Until 2030, Gazi University Journal of Science GU J Sci., 25(2), 495-503.

Tchobanoglous G., Kreith F.., (2002), Handbook of Solid Waste Management, Second Edition, McGraw-Hill, New York, 950ss.

TÜIK, (2017), Kişi Başı Ortalama Belediye Atığ Miktarl, Türkiye İstatistik Kurumu, https://biruni.tuik.gov.tr/medas/?kn=119\& locale $=$ tr, [Erişim 8 Aralık 2019].

TÜIK, (2018), Seragazı Emisyon İstatistikleri, 2016, Türkiye İstatistik Kurumu, http://www.tuik.gov.tr/PreHaber Bultenleri.do?id=27675, [Erişim 20 Şubat 2020].

TÜİK, (2019), Merkezi Dağıtım Sistemi, Türkiye İstatistik Kurumu, https://biruni.tuik.gov.tr/medas/, [Erişim 18 Aralık 2019].

US EPA, (2019), Overview of Air Pollution from Transportation, https://www.epa.gov/transportation-air-pollution-and-climatechange/learn-about-air-pollution-transportation, [Erişim 20 Aralık 2019].

Vu H.L., Bolingbroke D., Ng K.T.W., Fallah B., (2019), Assessment of Waste Characteristics and Their Impact on GIS Vehicle Collection Route Optimization Using ANN Waste Forecasts, Waste Management, 88, 118-130.

Wagner V., Rutherford D., (2013), Survey of Best Practices in Emission Control of In-Use Heavy-Duty Diesel Vehicles, International Council on Clean Transportation (ICCT), Washington D.C., USA, 64ss.

WHO, (2018), Ambient (Outdoor) Air Pollution, World Health Organization, https://www.who.int/news-room/fact-sheets/detail/ ambient-(outdoor)-air-quality-and-health, [Erişim 28 Kasım 2019].

WHO, (2020), WHO | Air Pollution, World Health Organization, https://www.who.int/sustainable-development/transport/health-risks/ air-pollution/en/, [Erişim 28 Kasım 2019].

Yalcinkaya S., (2020), A Spatial Modeling Approach for Siting, Sizing and Economic Assessment of Centralized Biogas Plants in Organic Waste Management, Journal of Cleaner Production, 255:120040, doi: 10.1016/j.jclepro.2020.120040.

Yalçınkaya S., Kırtıloğlu, O.S., (2020), Organik Atıkların Yönetimi Için Coğrafi Bilgi Sistemleri Tabanlı Çok Kriterli Karar Destek Sistemi Oluşturulmast: İzmir Örneği, TÜBİTAK ARDEB, İzmir.

Yapıc1, M., Koldemir, B., (2016), Yeni Teknoloji ve Alternatif Yakıt Uygulamalarının Hava Kirliliği Ile Römorkör Üretimine Etkilerinin Araștırılması, Journal of ETA Maritime Science, 4 (2), 105-12.

Yildiz Ş., Saltabas F., Yalcinkaya S., Kemirtlek A., (2009), Katı Atık Toplama ve Taşıma Optimizasyonu Kağıthane Örneği, Türkiye'de Katı Atık Yönetimi Sempozyumu Bildiriler Kitabı TÜRKAY 2009, 15-17 Haziran, İstanbul, ss.17-25. 